\title{
Average Concentration Normalized by Surface Area
}

National Cancer Institute

\section{Source}

National Cancer Institute. Average Concentration Normalized by Surface Area. NCI

Thesaurus. Code C92369.

AUCT AU divided by TAU and then divided by the surface area. 